
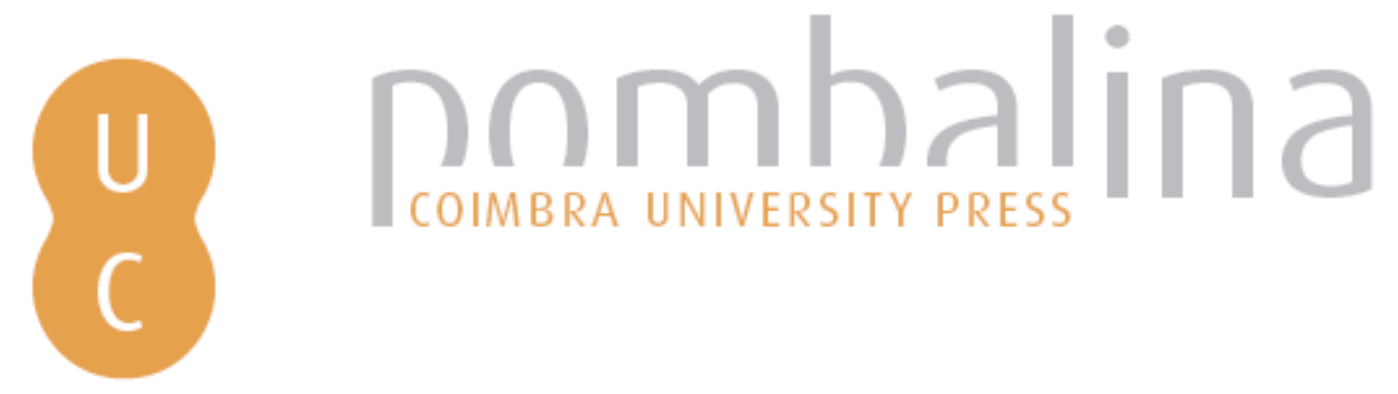

\title{
Espacios femeninos en la Castilla del antiguo régimen: cultura material y sociabilidad en el estrado
}

Autor(es): $\quad$ Sobaler Seco, M. ${ }^{a}$ Ángeles

Publicado por: Imprensa da Universidade de Coimbra

URL

persistente: URI:http://hdl.handle.net/10316.2/31585

DOI: $\quad$ DOI:http://dx.doi.org/10.14195/978-989-26-0201-1_6

Accessed : $\quad$ 26-Apr-2023 12:28:47

A navegação consulta e descarregamento dos títulos inseridos nas Bibliotecas Digitais UC Digitalis, UC Pombalina e UC Impactum, pressupõem a aceitação plena e sem reservas dos Termos e Condições de Uso destas Bibliotecas Digitais, disponíveis em https://digitalis.uc.pt/pt-pt/termos.

Conforme exposto nos referidos Termos e Condições de Uso, o descarregamento de títulos de acesso restrito requer uma licença válida de autorização devendo o utilizador aceder ao(s) documento(s) a partir de um endereço de IP da instituição detentora da supramencionada licença.

Ao utilizador é apenas permitido o descarregamento para uso pessoal, pelo que o emprego do(s) título(s) descarregado(s) para outro fim, designadamente comercial, carece de autorização do respetivo autor ou editor da obra.

Na medida em que todas as obras da UC Digitalis se encontram protegidas pelo Código do Direito de Autor e Direitos Conexos e demais legislação aplicável, toda a cópia, parcial ou total, deste documento, nos casos em que é legalmente admitida, deverá conter ou fazer-se acompanhar por este aviso.

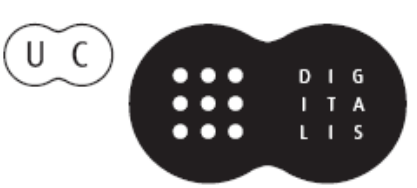


Isabel dos Guimarães Sá Máximo García Fernández (directores)

\section{PORTAS ADENTRO comer, vestir, habitar} (ss. XVI-XIX) 


\title{
ESPACIOS FEMENINOS EN LA CASTILLA DEL ANTIGUO RÉGIMEN. CULTURA MATERIAL Y SOCIABILIDAD EN EL ESTRADO
}

\author{
M. á ÁNGELEs SOBAlER SECO \\ Departamento de Historia Moderna ${ }^{1}$ \\ Universidad de Valladolid (España)
}

de ricas almohadas adornado, en tarimas de corcho, y por de fuera

el grave adorno de una y otra silla

Lope de Vega

\section{MUJER, ESPACIO DOMÉSTICO Y MENTALIDAD SOCIAL}

Dos tratados de arquitectura de finales del siglo XV, De Re Aedificatoria de León Baptista Alberti (1485) y los Comentari a l'económia d'Aristótil de Martí de Vicina (1492), señalan criterios sociales, morales y funcionales en la disposición de las dependencias domésticas, con la presencia de áreas públicas exteriores, y otras privadas más interiores, bien diferenciadas, donde hombres y mujeres tendrían sus espacios separados: la obra de Vicina, teñida de criterios morales sobre el papel de la mujer en la sociedad y en la casa, disponía que ésta se recluyera en las zonas interiores o secretas «lejos de la entrada de la casa», y próximas a las del servicio, la cocina y los dormitorios, mientras los hombres y sus

${ }^{1}$ Este trabajo se inscribe dentro del Proyecto de Investigación, financiado por la Junta de Castilla y León (referencia VA049A08), titulado Cultura material, consumo, moda e identidades sociales. Mujer, vestido y apariencia en Castilla y en León durante el Antiguo Régimen (siglos $X V I-X I X)$. 
invitados ocuparían los más externos, las salas de recibir, las habitaciones de invitados. Y en el mismo sentido Alberti recomendaba que las mujeres recibieran en esta distribución un «tratamiento no distinto al de los recintos consagrados al culto religioso y a la castidad» ${ }^{2}$.

Ambos tratados respondían a una moral social que promovía la separación por sexos de espacios públicos y privados, y que condujo a la definición de los que habían de ocupar las mujeres en la vida privada del hogar, y de los lugares y modos de su presencia en ámbitos públicos. En este sentido, la convencional función social asignada a la mujer durante el Antiguo Régimen, y las prevenciones consecuencia de su condición de depositaria del honor que obligaban a su protección, hicieron del hogar el escenario esencial de su quehacer diario. En la perfecta casada de Fray Luis de León, obra fundamental de la diplomacia doméstica y la educación de la mujer, se fijan los compromisos de la casada, gobernando la casa, educando a los hijos, atendiendo al marido, y siendo siempre buena administradora de su hacienda, moderada en el adorno personal y madre virtuosa. A principios del mismo siglo XVI, Antonio de Guevara en su Reloj de Príncipes (1529), entre los apartados que dedicaba a la orientación moral de princesas y grandes señoras cuya vida había de ser más ejemplar y recoleta que la del resto de las mujeres, argumentaba que:

Hora el marido esté presente, hora esté absente, cosa es necessaria y honesta que se esté la muger en su casa; porque desta manera las cosas de su casa yrán bien governadas y del coraçón del marido se quitarán muchas sospechas...

Y esto especialmente debería de entenderse entre las mujeres principales, para reputación de sus casas y ejemplo de las demás:

Diría yo que son obligadas las princesas y grandes señoras a residir y estarse en sus casas mucho más que no las mugeres baxas y plebeyas, y esta obligación les viene por alcançar más auctoridad y tener menos necessidad. $Y$ no sin causa digo que consiguirán más auctoridad; porque no ay virtud con que una muger alcance tanta reputación en la república con que vean todos que se está retrayda en su casa. Digo también que una señora deve estar muy retrayda a causa que bive con menos necessidad que otra; porque la muger pobre y plebeya, si sale, no sale sino a buscar de comer, pero la muger rica y generosa, si sale, no sale sino a se passear y regalar ${ }^{3}$.

\footnotetext{
${ }^{2}$ Cfr. Beatriz Blasco Esquivias, «Los espacios de la necesidad: alimentación, higiene y descanso nocturno», en La casa. Evolución del espacio doméstico en España, vol. I, Edad Moderna, Madrid, El Viso, 2006, p. 52.

${ }^{3}$ Antonio de Guevara, Relox de Príncipes (1529), Libro II, cap. VII, Valladolid, Nicolás Tierri, 1529.
} 
Siendo la casa el lugar donde la mujer daría cumplimiento a sus obligaciones, se le señalaron allí unos espacios privados que en sus variantes, recibieron denominaciones diversas: aposento de las mujeres, cuarto de damas... En la casa familiar castellana, las mujeres tuvieron su lugar reservado, el «estrado», un espacio elevado mediante tarima o delimitado dentro de una sala, amueblado según las posibilidades de cada familia, generalmente con cojines o almohadillas, asientos bajos, y con frecuencia presidido por alguna imagen religiosa, preferentemente de la Virgen, ejemplo de virtud femenina en todos sus estados. Lógicamente el estrado aparece en las viviendas acomodadas puesto que en las sencillas cualquier posibilidad de especialización funcional de los espacios es impensable. «En una sociedad y una cultura donde triunfaban el arte de la apariencia y el artificio, la propia diferenciación entre lo público y lo privado nos proporciona un criterio de bienestar derivado de la distribución interior de la vivienda de acuerdo con los usos asignados a cada estancia y asequible también a las casas principales de tipo medio, cuyo tamaño y organización espacial permitían delimitar claramente unas zonas abiertas de utilidad social (zaguanes, salas, estrados...) y otras cerradas de carácter privado e íntimo (dormitorios, alcobas, retretes...)». Esta ordenada especialización del espacio doméstica contrasta con «la obligada flexibilidad y versatilidad de las casas mínimas» ${ }^{4}$.

El primer diccionario del castellano, el Tesoro de la lengua (1611), de Sebastián de Covarrubias, definía el estrado en su segunda acepción como el «lugar donde las señoras se asientan sobre cojines y reciben las visitas». En siglo XVIII, el Diccionario de Autoridades (1720) lo precisaba como el «conjunto de alhajas que sirve para cubrir y adornar el lugar o pieza en que se sientan las señoras para recibir las visitas, que se compone de alfombra o tapete, almohadas, taburetes o sillas baxas». Y añadía «vale también el lugar o sala cubierta con la alfombra y demás alhajas del estrado, donde se sientan las mujeres y reciben las visitas».

El estrado como espacio doméstico, tuvo su origen en la España islámica y fue utilizado por los cristianos desde finales del siglo XII o principios del XIII. $\mathrm{Si}$ bien en principio fue compartido por hombres y mujeres, al menos desde el siglo XV se fue transformando en un espacio femenino. En él las mujeres, sentadas sobre cojines y almohadones con las piernas cruzadas ( «a la morisca» $\mathrm{O}$ «a la turca») se dedicaban a labores de aguja, recibían visitas, compartían lecturas edificantes en voz alta, rezaban el Rosario. Esta costumbre se desarrolló plenamente a lo largo de los siglos XVI y XVII. A finales del siglo XVII, la condesa D’Aulnoy se sorprendió al ser recibida en el Palacio de Monteleón en Madrid por más de sesenta señoras en un estrado, sentadas «con las piernas cruzadas... antigua costumbre que han conservado de los moros» sobre almohadones, en una estancia en la que sólo había una butaca para el príncipe de Monteleón, que sólo

\footnotetext{
${ }^{4}$ Blasco Esquivias, ob. cit., p. 50.
} 
acudía allí cuando las señoras se habían retirado. La misma dama francesa escribía que en España había mujeres que jamás se habían sentado en una silla... y que invitada en casa del hijo del duque de Alba, comieron las señoras de la casa y ella misma, en un mantel sobre la alfombra, mientras los caballeros lo hacían a la $\operatorname{mesa}^{5}$.

Los estrados femeninos tuvieron una considerable proyección en el espacio y el tiempo. Desde Castilla, la costumbre se extendió a las colonias americanas ${ }^{6}$, y su pervivencia se detecta aún en el siglo XVIII. En su viaje por España en 1705-1706, el dominico francés Juan Bautista Labat anotaba que «el uso de los sofás aún no se ha introducido en Cádiz, pero en la habitación de las mujeres hay un estrado alzado seis pulgadas, cubierto de alfombras, con cojines de terciopelo o de cuero según la estación, donde están todo el día (sentadas casi como nuestros sastres)» ${ }^{7}$. En una carta de 1756, un anónimo viajero se «sorprendía mucho al verlas alineadas y sentadas a todas en una alcoba llamada estrado» ${ }^{8}$. Esta costumbre de sentarse las mujeres en la tarima del estrado llamó la atención de Casanova en su viaje a España, y estando en Madrid, en 1768 comprobó varias veces esta costumbre de sentarse las damas «como africanas: costumbre de los moros que todavía permanece» ${ }^{9}$. Incluso consta en algunos testimonios del XIX la pervivencia de estrados, aunque de forma ya residual ${ }^{10}$ puesto que desde la llegada de los Borbones se aprecia su paulatino retroceso del estrado femenino doméstico, mientras se ampliaban las tertulias y salones donde asistía o presidían las mujeres.

Un amplio y variado conjunto de fuentes de información describen cómo era el estrado femenino, la organización de este espacio doméstico, su uso y funcionalidad y su trascendencia en el tiempo y en el espacio. Referencias literarias, obras de teatro o narraciones de ambiente urbano, tratados morales sobre comp. 149.

${ }^{5}$ Cit. por Alicia Cámara Muñoz, «Los espacios femeninos», en B. Blasco Esquívias, ob. cit.,

${ }^{6}$ El propio Diccionario de Autoridades (1720) recoge una cita de la obra del P. Alonso de Ovalle (S.J.), Historia de Chile, lib. 6, cap. 16: «Aquellas señoras, acostumbradas a su estrado y entretenimiento voluntario de su almohadilla, hubieron de sujetarse a tomar la escoba en la mano». Sobre las estrados de Ultramar ver el trabajo de María del Pilar López Pérez, «El objeto de uso en las casas de habitación de españoles y criollos en Santafé de Bogotá. Siglos XVII y XVIII en el Nuevo Reino de Granada», Anales del Instituto de Investigaciones Estéticas, ns. 74-75, 1999, especialmente en pp. 108-110.

7 «Viajes del padre Labat en España», en J. García Mercadal, Viajes de extranjeros por España y Portugal, t. IV, siglo XVIII, Valladolid, Junta de Castilla Y Léon, 1999, p. 518.

${ }^{8}$ «Cartas sobre el Viaje a España», en García Mercadal, ob. cit., t. V, siglo XVIII, p. 15.

${ }^{9}$ Cámara Muñoz, ob. cit., p. 147.

${ }^{10}$ En el trabajo aquí mismo presentado por la profesora Rosa Dávila, referente a la elite universitaria de Valladolid en el siglo XIX, la autora encuentra un caso entre la documentación consultada: el estrado de la madre política del profesor de medicina Pereda Repiso, en 1874, más dieciocho sillas y dos «confidentes». 
portamiento femenino, documentos notariales (testamentos, últimas voluntades, inventarios de bienes, dotes, escrituras de compraventa, contratos de obra...) y judiciales (pleitos y litigios), incluso producciones visuales de la época (pinturas, grabados, planos...) dan cuenta del tiempo que allí pasaban las mujeres y de las actividades que en ellos desarrollaban, definen normas de comportamiento social y moral femenino o señalan formas de trasgresión. Así mismo la acomodación y uso de este espacio doméstico llevaba consigo un mobiliario de estrado, unas piezas decorativas concretas, determinados útiles de labor, de oración y devoción. En las siguientes páginas trataremos de sintetizar esa información para mostrar el estrado como un espacio abierto de sociabilidad femenina y el desarrollo allí de una particular cultura material y simbólica, expresiva de la realidad social y mental de la mujer castellana de época moderna.

\section{EL ESTRADO: ENTRE LA VIRTUD Y LA SOCIABILIDAD FEMENINA}

El estrado era un espacio que las mujeres ocupaban después de cumplir con sus obligaciones domésticas. Un espacio para el descanso o el reposo, sin abandonar el hogar al que siempre debían estar atentas. Allí las mujeres de la casa solían emplearse en las labores de costura, acompañadas a veces con oraciones o tal vez con algunas lecturas, y allí también recibían las visitas y entablaban conversaciones.

La permanencia de la mujer en la casa diferenciaba a la virtuosa de la «mala mujer». Así lo advertía Fray Luis de León:

si la casada no trabaja, ni se ocupa en lo que pertenece a su casa, ¿qué otros estudios o negocios tiene en que se ocupar? Forzado es que, si no trata de sus oficios, emplee su vida, en los oficios ajenos, y que dé en ser ventanera, visitadora, callejera, amiga de fiestas, enemiga de su rincón, de su casa olvidada y de las casas ajenas curiosa, pesquisidora de cuanto pasa, y aun de lo que no pasa inventora, parlera y chismosa, de pleitos revolvedora, jugadora también, y dada del todo a la risa y a la conversación..." .

La mujer en casa debía permanecer activa, hacendosa, ocupada en sus obligaciones, evitando la ociosidad o la pereza, tan peligrosas casi como las inconvenientes salidas. Para los moralistas, la holgazanería de la mujer rompía su recogimiento y la conducía a la perdición del no hacer nada, dando en pensar demasiado o de forma inconveniente, o cayendo en los peligros del «espacio público». En 1547 el arzobispo de México Fray Juan de Zumárraga ensalzaba la laboriosidad como una virtud y dejaba claro que la pereza de las mujeres era

${ }^{11}$ Fray Luis de León, La perfecta casada, edición digital de la Biblioteca Virtual Miguel de Cervantes, cap. IX, p. 72. 
aborrecible a Dios: «La ociosidad en casa se huya; la cual es tan aborrecible a Dios, que todo lo que creó, luego, en creándolo, le dio su oficio ejercitándolo en algo» ${ }^{12}$. Y Fray Luis de León señalaba entre las virtudes de la perfecta mujer casada la de ser hacendosa, evitando el abandono de sus obligaciones y dando ejemplo con sus trabajos a las criadas y a las demás mujeres:

$Y$ a todas, sin que haya en ello excepción, los está bien y los pertenece, a cada una en su manera, el no ser perdidas y gastadoras, y el ser hacendosas y acrecentadoras de sus haciendas. Y si el regalo y el mal uso de agora ha persuadido que el descuido y el ocio es parte de nobleza y grandeza, y si las que se llaman señoras hacen estado de no hacer nada y de descuidarse de todo, y si creen que la granjería y la labranza es negocio vil contrario de lo que es señorio, es bien que se desengañen con la verdad ${ }^{13}$.

Para evitar todos los peligros de la holgazanería, las mujeres debían mantenerse ocupadas en las tareas propias, y después del cuidado de la casa y la educación de los hijos, lo eran los trabajos de aguja, porque era designio divino «ponerles la aguja en la mano, y ceñirles la rueca, y menearles el huso entre los dedos» ${ }^{14}$. A finales del siglo XVII, Antonio Ezcaray, Arzobispo de Nueva España, escribía que:

El espíritu Santo en los proverbios pinta a la mujer fuerte y casta, cuyo valor no tiene comparación con los tesoros del orbe, y dice de ella que trajo consigo el huso y la rueca para hilar, y hacer obras con las manos, para significarnos que todo va en una, ser mujer casta y honrada y hilar y trabajar, y sin duda no es de menos honor en una mujer saber jugar bien el huso y la abuja que en un hombre la espada y la daga ${ }^{15}$.

Este atributo de la costura era común a todas las mujeres de Europa y de Ultramar, sin distinción de estado o posición social. La obra moral y didáctica de Juan Luis Vives recordaba que las mujeres romanas al casarse, «traían a casa del marido husos, rueca y lana, y con ella coronaban las puertas de casa», y que la misma reina Isabel y sus hijas sabían «hilar, coser y labrar» ${ }^{16}$, como ejemplo para otras damas. Y Fray Luis de León recogía y ensalzaba las virtudes de las actividades femeninas que las apartaban de tentaciones y peligros:

${ }^{12}$ Fray Juan de Zumárraga, Regla cristiana breve (1547), Pamplona, Ed. Eunate, 1994, p. 53.

${ }^{13}$ Fray Luis de León, ob. cit., pp. 51-52.

${ }^{14}$ Ibidem, Prólogo.

${ }^{15}$ Fray Antonio Ezcaray, Vozes del dolor, nacidas de la multitud de pecados, que se cometen por los trages profanos, afeytes, escotados, y culpables ornatos, que en estos miserables tiempos, y en los antecedentes ha introducido el infernal dragón para destruir, y acabar con las almas, que con su preciosísima sangre redimió nuestro amantísimo Jesús (1691), Sevilla, por Thomás López de Haro, 1691, p. 255.

${ }^{16}$ Juan Luis Vives, Instrucción de la mujer cristiana (1524), edición digital de la Biblioteca Virtual Miguel de Cervantes. 
Así que, traten las duquesas y las reinas el lino, y labren la seda, y den tarea a sus damas, y pruébense con ellas en estos oficios, y pongan en estado y honra aquesta virtud; que yo me hago valiente de alcanzar del mundo que las loe, y de sus maridos, los duques y reyes, que las precien por ello y que las estimen; y aún acabaré con ellos que, en pago deste cuidado, las absuelvan de otros mil importunos y memorables trabajos con que atormentan sus cuerpos y rostros, y que las excusen y libren de leer en los libros de caballerías, y del traer el soneto y la canción en el seno, y del billete y del donaire de los recaudos, y del terrero y del sarao, y de otras cien cosas de este jaez, aunque nunca las hagan. Por manera que la buena casada, en este artículo de que vamos hablando de ser hacendosa Y casera, ha de ser, o labradora, en la forma que habemos dicho, o semejante a labradora todo cuanto pudiere $^{17}$.

Aún a finales del siglo XVIII, pese a los sutiles cambios de mentalidad respecto al ser femenino, una declarada defensora de las capacidades de las mujeres más allá del orden doméstico, Josefa Amar y Borbón, exaltaba las labores de aguja de las mujeres, aunque descargándolo de contenidos sagrados, diciendo que «tan bien parece una señora... con una rueca o una costura, como el letrado en su estudio, el artesano en su taller, el labrador en el campo... ¿quién negará que el labrado de los encajes de Flandes y de Inglaterra puede competir con el pincel más diestro?» ${ }^{18}$.

Todas las mujeres se empleaban en la aguja, aún cuando los trabajos de cada una subrayaran diferencias sociales: Las damas de clase alta realizaban bellos bordados; las de clase baja, zurcían la ropa y le daban vuelta una y otra vez como atestiguan algunos inventarios de bienes ${ }^{19}$. Algunas mujeres ayudaban a la economía doméstica con sus labores sin abandonar la casa: antes de la expulsión, las moriscas trabajaban la lana, el lino o la seda en sus hogare ${ }^{20}$, y entre las cristianas a lo largo de los siglos, muchas mujeres bordando casullas y otras ricas piezas de vestir en sus casas ${ }^{21}$.

Era costumbre también que mientras las mujeres cosían, bordaban o hilaban en el estrado, se empleasen en lecturas o en oraciones. Las primeras debían de ser preferiblemente sagradas y edificantes pero no faltaron otras lecturas de distracción o entretenimiento (novela y teatro) que debían ser moralmente conve-

\footnotetext{
${ }^{17}$ Fray Luis de León, ob. cit.

${ }^{18}$ Josefa Amar y Borbón, Discurso sobre la educación física y moral de las mujeres (1790),
} p. 160.

${ }^{19}$ Cfr. en Cámara Muñoz, ob. cit., p. 162.

${ }^{20}$ Bernard Vincent, «Las mujeres moriscas» en Georges Duby y Michelle Perrot (dirs.), Historia de las mujeres en Occidente, Madrid, Taurus, 1993, p. 587.

${ }^{21}$ Un buen ejemplo son las hacendosas protagonistas de las novelas de Mariana de Carvajal y Saavedra, siempre cosiendo y bordando para contribuir al sustento familiar (Navidades de Madrid y noches entretenidas, 1663). 
nientes. Entre las mujeres de familias acomodadas, obras piadosas y novelas de caballería se mezclaban con los útiles de labor. Lectura en ocasiones individual como la de una de las protagonistas de Zabaleta en Día de fiesta por la tarde (1659), una vez que el marido se va después de la comida, y dado que por ser día de fiesta «no puede trabajar y quiere divertirse», lee una novela de espaldas a la calle en un «balcón que es un aposento de celosías», aunque los ojos se le van de continúo hacia el exterior ${ }^{22}$. En otras ocasiones se trataba de lecturas colectivas, en voz alta, que una de las asistentes llevaba a cabo mientras el resto se empleaba en las labores de aguja ${ }^{23}$.

También la oración se daba en este espacio con un sentido colectivo o coparticipativo entre las asistentes, o en la soledad de la dueña de la casa. En Las harpías de Madrid y coches de las estafas, Alonso Castillo Solórzano (1631) cuenta como «entrando en la primera sala hallaron en un estrado a una señora viuda rezando en unas horas...» ${ }^{24}$. El estrado venía a ser una especie de complemento del «oratorio», espacio doméstico de oración que solían tener algunas casas de cierto nivel y cuya existencia recomiendan los moralistas, como Vives o Fray Luis León. La «sacralización» del estrado se llevaba a cabo mediante la disposición de alguna imagen religiosa (gravado, pintura, «escaparates», de bulto...) que expresaba la devoción de las damas. Y entre las oraciones convenientes, al menos desde finales del XVI, el Rosario sería la más acostumbrada.

Para la mujer virtuosa, el estrado era un espacio de tranquilidad, para eludir la holgazanería, aislarse de los males, vicios y tentaciones, recogerse en sus labores y oraciones. Pero la literatura moral da también otras versiones. Antonio de Guevara, a principios del siglo XVI, se imagina a la mujer «mala»y «holgazana», «arrellanada sobre una almohada», disfrutando de los placeres de la vida ${ }^{25}$. Como Guevara, otros moralistas observaron los peligros del estrado, especialmente como consecuencia de los encuentros que allí se celebraban.

Superando el modelo teórico definido por los moralistas del Siglo de Oro sobre la mujer aislada en el encierro doméstico, el estrado constituía un espacio para desarrollar la vida afectiva y social femenina. Allí era donde tenía lugar la conversación entre todas las mujeres de la casa y era allí donde la dueña recibía las visitas, generalmente de otras mujeres; visitas ordinarias y cotidianas previa invitación o anuncio, o las extraordinarias con motivo de celebraciones o duelos.

${ }^{22}$ Juan de Zabaleta, Día de fiesta por la tarde (1659), p. 387.

${ }^{23}$ Sobre lectura femenina ver Pedro Cátedra y Anastasio Rojo, Bibliotecas y lecturas de mujeres. Siglo XVI, Madrid, Instituto de Historia del Libro y de la Lectura, 2004. Sobre la aprobación o rechazo de la lectura y de saber escribir de las mujeres, Fernando Bouza, «Memorias de la lectura y escritura de las mujeres en el siglo de Oro», Historia de las mujeres en España y América Latina. El mundo moderno (dir. Isabel Morant), Madrid, Catedra, 2005, pp. 169-192.

${ }^{24}$ Alonso Castillo Solórzano, Las harpías de Madrid y coches de las estafas (1631), edición digital de la Biblioteca Virtual Miguel de Cervantes.

${ }^{25}$ Guevara, ob. cit., p. 389, n. 65. 
En palabras de Alicia Cámara, «la celosía, el coche y el estrado fueron los tres lugares desde los que la mujer se relacionó con el exterior de la casa, además de la misa y las visitas» ${ }^{26}$.

Las visitas debían ser ajustadas y convenientes, y los moralistas no dejaron de ver en ellas una amenaza para el pudor y la honra femenina. Aunque Vives señalara que «pasa peligro la mujer en estar sola y ociosa... porque el ánimo de la mujer es ligero y en pocas partes halla puerto seguro», no dejaba por ello de observar el pecado de la vanidad femenina al referirse a las «visitas que ahora se usan», donde concurren «veinte o treinta mujeres asentadas juntas. Si alguno pone los ojos en ellas... todas se estremecen de placer pensando cada una que lo han por su gentil rostro amoroso y con esto comienzan todas a reír... Con todo no es cosa de burla ver que cada una con su personaje piensa ser mirada de todo el mundo; y luego se para tan ancha toda ufana y la cresta muy yerta como gallo. En todo su seso jurará que entre todas las que allí están, no hay ninguna que le eche el pie delante ${ }^{27}$.

Como Vives, otros autores señalaron los peligros de estos frecuentes y concurridos encuentros, denunciando los excesos de la palabra, de los refrescos, de la ostentación y la vanidad. En fechas próximas Antonio de Guevara condenaba «que las mugeres se anden de casa en casa a visitar», indicando los graves inconvenientes de las salidas de la casa propia y las entradas en las ajenas:

Las señoras generosas y que son de su honra zelosas deven mucho mirar y considerar los grandes inconvenientes que de mucho visitar se les puede seguir, ca las tales han de gastar mucho para se vestir, han de perder mucho tiempo en se adereçar, han de sustentar familia para las acompañar, han de aver enojo con los maridos sobre si han de yr, han de acontescer malos recaudos en sus casas por ellas se absentar, a todos los amigos y enemigos han de dar que dezir...

Más adelante denuncia que:

muchas señoras se escusan por enfermedad de yr siquiera una vez a missa en la semana, y después vémoslas sanas y buenas para visitar a sus amigas cada día, y (lo que es peor de todo) que no quieren yr a la mañana con la fría a la iglesia y después con el calor ándanse a visitar de casa en casa...

No sólo se daba pie a la vanidad y se eludían otras obligaciones domésticas o espirituales. Guevara detalló también los peligros y desviaciones de esos encuentros femeninos frecuentes, en la conversación, en la apariencia y en el agasajo:

\footnotetext{
${ }^{26}$ Cfr. Cámara Muñoz, ob. cit., pp. 163-164.

${ }^{27}$ Vives, ob. cit., p. 112.
} 
Ya que se juntan en una casa muchas señoras, es verdad que son cosas graves las que se tratan entre ellas. Dígolo porque se juntan o a comer frutas, o a loar los linajes, o a hablar de los maridos, o a trocar labrados, o a cotejar las ropas, o a notar las mal vestidas, o a tachar las fermosas, o a reýrse de las feas, o a murmurar de las vezinas y (lo que más de notar es) las mismas que dizen mal de las que están en ausencia, aquellas mismas se muerden unas a otras de embidia... ${ }^{28}$.

La literatura del siglo XVII recoge referencias varias a este respecto. En el entremés de Cervantes El viejo celoso, el protagonista denunciaba que «no les vienen los malos aires a las mujeres de ir a lo[s] jubileos ni a las procesiones, ni a todos los actos de regocijos públicos; donde ellas se mancan, donde ellas se estropean y adonde ellas se dañan, es en casa de las vecinas y de las amigas; más maldades encubre una mala amiga, que la capa de la noche; más conciertos se hacen en su casa y más se concluyen, que en una asamblea» ${ }^{29}$. Castillo Solórzano en Las harpías de Madrid (1631) describe un entremés preparado en la casa de una dama:

Quiso la señora Luisa que esta fiesta fuese aplaudida de damas, y así convidó a las dos amigas y a su madre... y a prima noche vinieron en el coche juntamente con ellas otras amigas de aquel barrio, mozas y bizarras. Prevínose la sala de luces y de pomo en el brasero que exhalaba suavísimo olor, acomodándose en su estrado, y el genovés en una silla cerca del, de donde podía hablar a gusto con su dama ${ }^{30}$.

Zabaleta en su Día de fiesta por la tarde (1659) describe con buena carga de ironía la recepción de la visita: van llegando las damas invitadas y entrando en la casa, se dirigen al estrado interior donde las recibe la anfitriona y toman asiento; allí comienza la conversación a ratos interrumpida por el servicio del agasajo o refresco. ¿De que haban las mujeres? al principio, «empezose a tejer entre todas una conversación muy como suya: hablan de galas y aliños». Interrumpe luego el tema la llegada del «chocolate», y tras su degustación comienzan los comentarios sobre celos y maridos, y acaban en el cotilleo sobre otras mujeres. «Prosiguiose la murmuración, y no pararon hasta que se despidieron». Zabaleta critica este gusto femenino por las conversaciones banales y la murmuración que deriva con frecuencia en ataques a la reputación ajena ${ }^{31}$. Confirmando esta descripción, a finales del siglo XVII madame D’Aulnoy en su

\footnotetext{
${ }^{28}$ Guevara, ob. cit., libros VII y VIII.

${ }^{29}$ Miguel de Cervantes Saavedra, Entremeses, ed. E. Asensio, Madrid, Castalia, 1971, p. 209.

${ }^{30}$ Castillo Solórzano, ob. cit., Después de instalados allí los concurrentes, recibieron a tres músicos y otro caballero que con sus guitarras y voces interpretaron unas letrillas ante aquel público asistente.

${ }^{31}$ Zabaleta, ob. cit., pp. 357-369.
} 
supuesto viaje a España, describía cómo las mujeres españolas recibían en el estrado a las visitas, que la anfitriona se levantaba para recibir a cada una que llegaba, y cómo la conversación amenizaba las horas de las mujeres, acompañada del refresco ${ }^{32}$.

Desde la versión de los moralistas, en 1691 Antonio Ezcaray condenaba las visitas alegando que:

De la frecuencia de visitas se siguen muchos daños, e inconvenientes, $y$ no pocas veces graves ofensas de nuestro Señor. El primer daño es la pérdida del tiempo, pues se están los días de fiestas, y los mas entre semana toda la tarde, y la mayor parte de la noche las mujeres en vanas conversaciones, meriendas, juegos, y entretenimientos, sin cuidar de sus casas, sin hilar, ni hacer otra labor decente a su estado, y en muchas necesario para el sustento de su familia ${ }^{33}$.

Desde la literatura o desde la moral, los autores insistían en la superficialidad de la conversación y los placeres del agasajo que suponían una desviación de las obligaciones y quehaceres femeninos convenientes. Precisamente por ello se señaló lo inapropiado de la asistencia de las hijas de la familia a esas conversaciones, para evitar que «la vista, el pensamiento y el deseo» se pusieran en funcionamiento, como escribía Arbiol en $1739^{34}$.

Más allá de miedos y restricciones, se procuró la normalización del hábito de las visitas, cada vez más comunes y de moda, y se fijaron reglas de protocolo que aseguraban comportamientos sociales y morales a la vez. Un texto anónimo de finales del XVIII, bajo el título El ceremonial de estrados y crítica de visitas, con tono de crítica irónica, muy al gusto del ilustrado siglo XVIII, describía el modo adecuado de recibir y organizar las visitas que hacían y recibían las mujeres, según la moda y para «asegurar la opinión». Justifica la obra el autor porque en Madrid «en donde la primera atención, y cuidado de las señoras, ante todas cosas, es como han de cumplir con sus amigas, esté tan olvidado el ceremonial», por lo continuamente se ofrecen mil quiméricas disputas en las mugeriles tertulias» ${ }^{35}$. A continuación, en sucesivos capítulos, va desgranando los tipos de visitas y sus correspondientes recibimientos «quando viene alguna

${ }^{32}$ Condesa D'Aulnoy, Viaje por España en 1769, Barcelona, Círculo de Lectores, 2000.

${ }^{33}$ Fray Antonio Ezcaray, Vozes... ob. cit, p. 255. Sobre las conversaciones de las mujeres ver también el capítulo correspondiente de Carmen Martín Gaite, Usos amorosos del dieciocho en España, Madrid, Editores S.A., 1972.

${ }^{34}$ Antonio Arbiol, La familia regulada (1739).

${ }^{35}$ El título por extenso es El ceremonial de estrados y crítica de visitas. Obra útil, curiosa $y$ divertida, en que con estilo jocoserio se describe como deben hacerse las visitas de bienvenida; de boda; de parida; de duelo; las diarias, y otras cosas que tocan y atañen al propio asunto, y deben saberse y observarse por las Damas que no quieren pasar plaza de poco cultas, Madrid, impr. de Antonio Espinosa, 1789. El referido texto explicativo de intenciones, aparece en el prólogo (pp. 7-9). 
Señora de fuera», «quando hay boda», «en visita de parida», «en el duelo del marido o parientes» y por supuesto, «quando hay recibo, y en las visitas de todos los dias». No falta en cada apartado lo correspondiente a la forma en que han de citarse y recibirse, al oportuno agasajo y los obsequios, qué se debe decir o como se divierten las damas en estos encuentros, añadiendo además el modo como ha de corresponderse a la invitación. En cada uno de los apartados se hace referencia al espacio doméstico donde esas recepciones han de tener lugar (estrado), salvo en el último capítulo que se refiere a paseos y acompañamientos en la calle. Tienen interés en cada apartado el protocolo de la invitación y su aceptación, el recibimiento de las «amigas» y el refresco en cada caso apropiado, señalando el estrado como escenario de encuentros y celebraciones femeninas ${ }^{36}$.

Si bien otros lugares (la calle, la iglesia, los toros, el teatro, las comedias...) no dejaron de ser visitados por las damas y por mujeres de casi cualquier condición social, derrumbando el ideal de la mujer recluida, queda fuera de toda duda que en el ámbito doméstico, escenario de sus actividades, el «estrado» se muestran como un espacio de sociabilidad femenina. Por ello era importante poner especial celo en a quién se recibía, por los peligros de las visitas engañosas que señalara Fray Luis de León:

una de las virtudes de la buena casa y mujer, es el tener grande recato acerca de las personas que admite a su conversación y a quien da entrada en su casa; porque, debajo de nombre de pobreza, y cubriéndose con piedad, a las veces entran en las casas algunas personas arrugadas y canas, que roban la vida, y entiznan la honra, y dañan el alma de los que viven en ellas, y los corrompen sin sentir, y los emponzoñan, pareciendo que los lamen y halagan ${ }^{37}$.

Ante tales peligros se proponía el remedio radical, el apartamiento de toda relación o contacto fuera de la casa, a lo que coadyuvaba el estado de matrimonio como aconsejaba Francisco Cascales en su Epístola a Doña Antonia Valero de Eslava, uno de cuyos párrafos encabezaba aconsejando «dar estado a la mujer, y quitarla de las ocasiones, no sólo de vecinos conocidos, pero [de] la comunicación de parientes» ${ }^{38}$.

Más que aquellas amenazantes entradas de personas «peligrosas» en el estrado, preocupaban las presencias masculinas, consideradas poco o nada convenientes, y observadas con recelo por lo que suponían de pábulo a los rumores y amenaza a la honra familiar. En principio se consentía de forma excepcional recibir visitas de varones dignos de confianza: el marido, los parientes y deudos

${ }^{36}$ Ibidem.
${ }^{37}$ Fray Luis de León, ob. cit.
${ }^{38}$ Francisco Cascales, Cartas filológicas, Epístola Primera (Libro III) A Doña Antonia Valero de Eslava (Con una instrucción para las doncellas que han de ser casadas); www.ensayistas.org/antologia/XVII/cascales/index.htm. 
próximos o clérigos. Entre las damas de calidad se acostumbraba a recibir visitantes ilustres, como cuando la virreina de Valencia recibió la visita del cardenal Barberini y su séquito, que fueron sentados en sillas, mientras ella y otras damas lo hicieron en almohadones; o cuando él mismo visitó a la duquesa de Pastrana en su estrado con solo una silla para que se sentara el cardenal, y con una «fila de ocho o diez cojines para las damas, que se sentaron encima ${ }^{39}$. Otras veces el encuentro se producía con motivo de algún festejo. Alonso Castillo Solórzano describe al grupo se damas y caballeros que se reunieron en unas casas en tiempo de carnaval. En la primera,

Entráronse aquellos caballeros y damas en una espaciosa sala, colgada de costosos paños flamencos y alfombras turcas. Estaban repartidas por ella muchas luces, con igual correspondencia. A un lado estaba un grande estrado, con veinticuatro almohadas de terciopelo carmesí; en él había dos grandes braseros de plata, para reparo del frío, que le hacía grande;

Luego describe otra casa y encuentro semejantes:

Ocuparon sus asientos las damas en un largo estrado, y los caballeros en las sillas más cercanas a él, procurando que les alcanzase parte del calor del fuego, que tenían dos grandes braseros de plata, y de la fragancia que daban dos bien aderezados pomos que en ellos había ${ }^{40}$.

Juntos pero sin sobrepasar los límites. Los hombres que accedían al estrado se sentaban en sillas bajas o taburetes, fuera de la marca de un balaustre o una estera o alfombra, y cabía señalar incluso el grado de confianza por la cercanía del asiento del varón a la mujer en el estrado.

Los textos abundan en referencias a los contactos entre hombres y mujeres que tienen lugar en el estrado, no siempre respetando la separación de espacios, y ante esa evidencia, aparecen también los tratados morales advirtiendo de los peligros y proponiendo remedios. Antonio de Guevara, haciendo recapitulación de los argumentos contra visitas y salidas de las mujeres, exponía los peligros de las entradas de varones a visitar a las casadas:

Es tan mirada, es tan delicada la honra de las mugeres, que si no les damos licencia para que salgan de sus casas a visitar, menos se la daremos para que sean visitadas; porque visitarse las señoras unas a otras aun parece piedad, pero visitar los hombres a las mugeres es gran desonestidad. En pre-

${ }^{39}$ En el Diario del viaje a España del Cardenal Francesco Barberini escrito por Cassiano del Pozo (1626), edición crítica de Alessandra Anselmi, Madrid, 2004. Cfr. Beatriz Blasco Esquivias, ob. cit., pp. 148 y 150. Asombrado el relator describía el estrado donde las damas «se colocan en verano sobre una estera finísima, que viene de la India, y en invierno sobre alfombras turcas».

${ }^{40}$ Alonso Castillo Solórzano, Tiempo de regocijo, Madrid, Bibliófilos Españoles, 1907, p. 195. 
sencia de sus maridos o de sus parientes propincuos pueden las mugeres ser comunicadas y visitadas, y esto se entiende de personas aprovadas y honestas; pero diría yo que, no estando el marido en casa, sería sacrilegio que algún varón osasse passar el umbral de la puerta...

Muy estraño ha de ser a la muger cuerda pensar que puede tomar plazer fuera de su casa; porque en su casa tiene a su marido con quien hablar, tiene a sus hijos a quien enseñar, tiene a sus hijas que doctrinar, tiene a su familia con quien conversar, tiene a su hazienda que governar, tiene a su casa que guardar, tiene a sus parientes con quien cumplir. Pues si dentro de su casa tienen tantos passatiempos, ¿para qué admiten visitaciones de hombres estraños? De tener las mugeres casadas particulares amicicias, y folgar de visitar y ser visitadas, suele dello suceder en que Dios sea ofendido, el marido injuriado, el pueblo escandalizado y aun la muger casada saca dello poco provecho y la que es por casar saca no buen casamiento... ${ }^{41}$.

Existe referencia a este tipo de encuentros bien conocidos, entre las páginas de la literatura del Siglo de Oro. En una de los episodios relatados por Cervantes en el Quijote, un caballero que espera a su amigo en una silla junto al estrado, expresa su deseo de descansar un instante, respondiéndole la dama «que mejor reposaría en el estrado que en la silla» ${ }^{42}$. En la segunda parte del Guzmán de Alfarache, la novela de Mateo Alemán (1604), se describe el engaño a una casta mujer casada por un pretendiente con la intervención de una mediadora que consigue hacerle llegar a casa de la engañada, y «quedándose sola Dorotea... Claudio entró luego y, tomando en el estrado una de aquellas almohadas junto a Dorotea, le comenzó a hacer muchos ofrecimientos....»3. En Las harpías de Madrid (1631), el autor relata la visita de un caballero a una dama que lo recibe en el estrado, y para confesarle las razones de su pena le invita a acercarse:

Entrad la silla en el estrado, que no querría aún echar el aliento de la boca, porque me temo que me han de oir ${ }^{44}$.

En las Aventuras del Bachiller Trapaza de Castillo Solórzano (1637), una dama celosa y engañada sorprende al protagonista «sentado en la almohada de un estrado y en otra a doña María, muy gustosos y conformes» ${ }^{45}$. En varios de

${ }^{41}$ Guevara, ob. cit., Libro II, cap. VIII.

42 Utilizo la edición digital de Don Quijote de La Mancha, preparada por el Instituto Cervantes, dirigida por Francisco Rico, 2004, p. 514. Son varios los pasajes de esta obra universal donde se refieren mujeres en estrados o se hace referencia al rico adorno de almohadas con que se cubrían para señalar la posición de la dama.

${ }^{43}$ Mateo Alemán, Guzmán de Alfarache (1604, edición de Francisco Rico, Barcelona, 1987, p. 725.

${ }^{44}$ Castillo Solórzano, Las harpías de Madrid... (1631).

45 Alonso Castillo Solórzano, Aventuras del Bachiller Trapaza (1637), edición digital Biblioteca Virtual Cervantes. 
sus relatos escritos en el XVII, María de Zayas y Sotomayor describe escenas íntimas en el estrado, compartido por hombres y mujeres, del enamorado que para hablar con su amada le pidió ir a la «parte más oculta», y fue conducido hasta el estrado donde ella tenía su cama, del amante que allí se deleitaba con su dama sobre los almohadones, o del marido que duerme allí la siesta con su mujer para evitar provocarle celos 46 .

Hay que insistir en la distancia entre el espíritu director de los textos de los moralistas y la vida y el comportamiento real de las mujeres. Muchos testimonios de la época indican que la vida de la mujer no era ni recluida ni tan aburrida, ni siquiera entre los muros de las casas. La recepción de visitas donde no quedaban excluidos los varones, la conversación entre asistentes, la progresiva inclusión de lecturas, representaciones y música, y la multiplicación de estas recepciones, situarían a los estrados, creados como refugio de la virtud femenina, en la antesala de los salones y tertulias introducidos por la influencia extranjera y las ideas ilustradas del siglo XVIII, y donde cobraba protagonismo la presencia femenina, ahora mezclada con los varones asistentes. La transición fue lenta y difícil. Durante la primera mitad del siglo, en palabras de Martín Gaite, «las damas no consiguieron romper, más que excepcionalmente, con el envaramiento y empaque que les eran proverbialmente habituales, y como consecuencia de esta actitud, las reuniones a que asistían con el solo fin de abanicarse, serias y patéticas en un rincón, mientras los hombres en otro jugaban a las cartas, venían a convertirse en una mera supervivencia del estrado, cuya impronta llevaban» ${ }^{47}$. No obstante había ido cambiando la actitud en el estrado, donde las labores eran abandonadas y las presentes se mostraban más interesadas en la conversación o las ventanas:

entraron y encontraron en el estrado más de una docena de mujeres a cual más bizarra y más empapillotada. Notó D. Jacinto que aquellas mujeres tenían poquísimo asiento, pues no cesaban de mudar puestos y buscarse unas a otras; y cogidas por mano andaban de balcón en balcón hechas unas cotorras ${ }^{48}$.

Por las mismas fechas se expresaban protestas contra la injerencia de los hombres en los estrados:

...la frecuencia de las empresas amorosas que se ven y se oyen, las continuas conversaciones de amor en los estrados, el trato familiar con hombres

\footnotetext{
${ }^{46}$ La referencia genérica a las obras de esta autora del siglo XVII en Cámara Muñóz, $o b$. cit., pp. 147-148.

${ }^{47}$ Carmen Martin Gaite, Usos amorosos del Dieciocho español, Madrid, Editores S.A., 1972, p. 33.

${ }^{48}$ Del relato de Antonio Muñoz, en Aventuras en verso y prosa (1739), cit. por Martín Gaite, pp. 32-33.
} 
profanos y otras noticias dejan mucho desconsuelo en el corazón de un hombre sensato ${ }^{49}$.

Los cambios serán más fluidos en la segunda mitad del siglo conforme se difundan los gustos extranjeros y se liberan las costumbres. No obstante, la identificación del estrado como el lugar donde recibían las mujeres españolas que al ir desapareciendo en el ámbito doméstico habrá en su lugar «salones de estrado» aunque sin la presencia de la tarima delimitada y con las mujeres sentadas en sillas altas ${ }^{50}$. Sirva de ejemplo a los cambios incluso desde la moral convencional, el texto del jesuita Antonio Ossorio de la Cadena, La virtud en el estrado. Visitas juiciosas. Crítica espiritual (1766), donde en forma de diálogos instructivos, cuatro mujeres -dos jóvenes y doncellas y sus respectivas madres-, advierten contra el comportamiento libertino de las doncellas, condenan el vicio femenino de la murmuración y los excesos de la vanidad, aconsejando recato en la apariencia y prudencia en la palabra. En todo, el texto recoge la esencia de los moralistas que le precedieron, pero los referidos diálogos se desarrollan en buena parte en la calle, durante el paseo, y no en el recato del hogar. La casa quedaba como resguardo de las doncellas, cuidando las madres de la honesta conversación y las recatadas y ajustadas visitas, evitando las frecuentes visitas de caballeros, y de contra modas y vanidades:

no las dexes salir de casa, ni andar vagueando por la Ciudad; porque eso no solo desdice de una mujer de obligaciones, sino también es indicio de mugeres perdidas ${ }^{51}$.

En cualquier caso, queda en el título del texto la nostalgia moral de lo que tiempo atrás había debido significar el ideal del estrado femenino.

\section{CULTURA MATERIAL Y CONSUMO EN EL ESTRADO}

Pese a su carácter doméstico y privado, el estrado es un espacio expuesto a la mirada de las visitas. En una sociedad donde la apariencia tenía un papel fundamental, para afirmar posiciones y reforzar calidades, esto obligaba a un esfuerzo por convertirlo en un foco de ostentación y admiración. Por ello, en el estrado se desarrolló una importante riqueza decorativa expresada en la especificidad del mobiliario y la decoración.

\footnotetext{
${ }^{49}$ Diario de Literatos (1738), t. IV, p. 299; cit. en Martín Gaite, ob. cit., p. 24, n. 5.

${ }^{50}$ Cámara Muñóz, ob. cit., p. 149.

${ }^{51}$ Antonio Ossorio de la Cadena, La virtud en el estrado. Visitas juiciosas. Crítica espiritual, Madrid, Impr. Andrés Ortega, 1766, p. 40.
} 
El estrado no se identifica con una habitación, es más bien un lugar, definido por estar algo elevado, delimitado y ricamente adornado, que podía formar parte de una sala principal de la casa o estar en la alcoba de la señora, para visitas de más confianza. En realidad no tienen por qué haber un solo estrado en una casa. Todo dependía de las posibilidades de los dueños de las casas, aunque generalmente había más de uno: en la de un noble zaragozano en 1548 había cinco, dos de ellos principales y otros secundarios o accesorios, de menor valor en la tasación; En Madrid, la casa del Conde de Salvatierra luego de la Duquesa de Arcos y por último de los Duques del Infantado, encontramos aún en el siglo XVIII, tres estrados en tres salones contiguos, al final de los cuales se encontraba el «gabinete dorado»; también la casa proyectada por Churriguera para los Sentmenat en Barcelona se observan dos salas de estrado, la segunda más privada, se comunica con el dormitorio que a su vez dará a un tocador, y con el oratorio.

También la literatura recoge este número de estrados en las casas. La mejor descripción, como ya hemos señalado, la de Zabaleta, ofreciendo una de las posibilidades de desarrollo del espacio doméstico femenino y su decoración. Aquí se relata el recorrido de las visitas desde la entrada hasta la zona de los estrados, en este caso tres; el primero sin uso como evidencia el brasero apagado, es el llamado «estrado de respeto», el segundo «de cumplimiento», y el tercero «de cariño», más íntimo, cerca del dormitorio ${ }^{52}$. Aunque se trata de una disposición ideal, recrea con acierto un arquetipo nada infrecuente, y que obligaría a introducir restricciones mediante leyes suntuarias. En sus Avisos sobre la corte madrileña, Jerónimo de Barrionuevo da noticia de que el 21 de de noviembre de 1654 se legisló «para que las señoras... no tengan tres estrados, coches de 6 mulas, trajes y otras vanidades, al paso que España se va perdiendo ${ }^{53}$.

El número de estrados y su amplitud -recuérdese el número tan abultado de asistentes en las visitas- eran signo de poder y posición. Pero lo que verdaderamente daba valor al estrado era el acondicionamiento, el mobiliario y la decoración. «El estrado era puro tejido, era tela hecha casa, con sus alfombras, sus almohadones, sus paños para todo uso, sus arrimaderos en las paredes, incluso en el hecho de que allí se cosiera, que era una de las funciones de la señora de la casa» ${ }^{54}$. De los estrados del siglos XVIII, según Abad Zardoya, sabemos que los cojines se rellenaban de pluma, de lana o de borra, y se forraban con sedas, en forma de damascos o brocados para las grandes ocasiones, o bien de simple cañamazo para el uso diario ${ }^{55}$.

\footnotetext{
${ }^{52}$ Zabaleta, ob. cit., pp. 350-351.

${ }^{53}$ Jerónimo de Barrionuevo, Avisos del Madrid de los Austrias y otras noticias, Madrid, editorial Castalia, 1996, p. 110.

${ }^{54}$ Cámara Muñoz, ob. cit., p. 150.

${ }^{55}$ Carmen Abad Zardoya, «El estrado, continuidad de la herencia islámica en los interiores domésticos zaragozanos de las primeras cortes borbónicas (1700-1759)», Artigrama, n. 18, 2003, pp. 375-392.
} 
La literatura contemporánea no dejaba de hacer hincapié en la riqueza y colorido de los textiles de los estrados, buscando armonía, belleza. María de Zayas describe el estrado verde desde el que la bella Lisis presenció una fiesta en su casa: almohadas de terciopelo verde con borlas y guarniciones de plata, tapices flamencos con flores y arboledas, brocados verdes con flecos y alamares de oro, y en derredor de toda la estancia sillas de terciopelo verde para los caballeros. En una estancia caldeada por un gran brasero de plata, que daba un rico olor $^{56}$. En la novela de Mateo Alemán de principios del XVII, el pícaro protagonista Guzmán de Alfarache describía los ricos bienes con que iba llenando su casa de Madrid, en un golpe de la fortuna:

colgaduras de invierno y verano, tapices de Bruselas, brocateles, camas de damasco, pabellones, colchas, alfombras, almohadas de estrado y otros muebles dignos de un señor ${ }^{57}$.

En las Aventuras del Bachiller Trapaza (1637), un caballero visita a una viuda y la encuentra en su estrado:

Estaba en una cuadra colgada de tapices pardos de bordaje, adorno de casa de viudas, un estrado de veinte y cuatro almohadas de terciopelo negro, que estaban sobre una almohada de buen tamaño, blanca, parda y negra; a los lados, dos bufetillos de ébano y marfil, muy curiosos, y en el que la viuda tenía a su lado estaba un pequeño contador de las mismas maderas.

Más adelante visita el mismo protagonista otra casa en la calle del León, donde encontraron «una mujer anciana sentada en un estrado negro, por quien mostraba tener estado de viuda» ${ }^{58}$. Los estrados de viudas son mencionados con frecuencia en la literatura del XVII: llegadas a Madrid las dos damas sevillanas e instaladas en una casa de viuda, adornaron el cuarto «(por ser con menos costa) con aderezos de casa de viuda, colgaduras honestas, estrado negro, sillas, bufetes y lo demas al tono desto, muy a imitación de la vecina del cuarto bajo» ${ }^{59}$.

Testamentos, últimas voluntades, dotes, inventarios de bienes, escrituras de compraventa o contratos de obras, en los que intervienen las mujeres como contratantes principales, se suelen detallar muebles, ropas y útiles domésticos, porque las mujeres «tenían una relación emocional con los enseres domésticos y los efectos personales ${ }^{60}$. Allí aparece la referencia a los complementos del estrado.

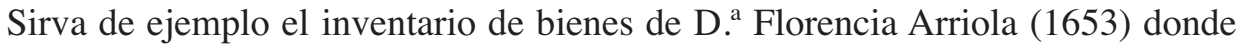
se refieren:

${ }^{56}$ María de Zayas, Novelas amorosas y ejemplares (1637), edición digital Biblioteca Virtual Miguel de Cervantes.

${ }^{57}$ Mateo Alemán, ob. cit., p. 838.

${ }^{58}$ Castillo Solórzano, Aventuras del Bachiller... (1637).

${ }^{59}$ Castillo Solórzano, Las harpías de Madrid (1631).

${ }^{60}$ Cfr. Cámara Muñoz, ob. cit., p. 165 y n. 236. 
«varias esteras de esparto.

Yten una estera fina grande de paxa del estrado.

Yten otra estera blanca y negra del estrado.

Yten otra estera del estrado ${ }^{61}$.

En estos instrumentos se mencionan «sillas de estrado», «taburetes de estrado», tapices, mesillas bajas, arquetas, escritorios, aparadores, o bufetes para guardar los hilos, que se utilizaban en el estrado de las mujeres; los «mullidos», haciendo referencia al conjunto de cojines y almohadones que llenaban estos espacios, $\mathrm{o}$ «arrimaderos» como se denominaban los tapices, alfombras y esteras con que se cubrían suelo y paredes para decorar y aislar de fríos y humedades. En la documentación notarial puede aparecer también la expresión «estrado completo» para referirse al conjunto de «alhajas», muebles y objetos propios de esta pieza. En el mismo sentido también constan expresiones semejantes en este sentido en pleitos y litigios. Junto al mobiliario y objetos de decoración se citan también otros específicos para la costura: ruecas y husos, bastidores para bordar. No era extraño que en los estrados se dispusieran «escaparates» relicarios, imágenes religiosas. Y braseros para templar el ambiente o candelabros para iluminar.

Por otro lado, el estrado estimulaba el consumo de ciertas golosinas muy apetecibles a las mujeres, y las visitas eran ocasión para disfrutarlas pues allí la anfitriona cumplimenta a la visita con el agasajo. La completa descripción de Zabaleta sobre las visitas del estrado en día de fiesta por la tarde, da buena muestra de cómo debieron ser y que era lo que se consumía allí:

Interrumpió la conversación el chocolate. A esta manera de merienda, porque le viene largo el nombre, le llaman agasajo. Salieron con él dos doncellas que, arrodilladas, le servían. La bebida es saludable, el modo de servirla injusto.

El autor critica la forma de servir humillada de las doncellas, expresión de la soberbia de los ricos. Luego de consumido el chocolate, «Recogen las criadas las vasijas en que han bebido el chocolate, y quedan las visitas alabándole. Habla cada una en el que tiene en casa», y después de otros comentarios sobre «cosas de comer», acaban por referirse a las bondades de la «leche helada» hasta que la dueña solicita a sus criadas la traigan. Finalmente, quejándose una de las damas de lo frío que le quedó el estómago, responderá la anfitriona haciendo sacar «hipocrás» (mezcla especiada de vino con miel), y bebieronlo todas solo porque lo vieron» ${ }^{62}$.

${ }^{61}$ Cfr. Juan José Martín González, La arquitectura doméstica del Renacimiento en Valladolid, Valladolid, Imprenta Castellana, 1948, p. 274. El autor describe alguna de las casas principales del Valladolid del XVI, mencionando en ellas algunos «cuartos de damas» donde se encontraba el estrado, como en la del Licenciado Butrón (p. 162).

${ }^{62}$ Zabaleta, ob. cit., pp. 361, 366, 367 y 369. 
En el mismo sentido, el irónico Ceremonial de estrados de finales del siglo XVIII, recoge puntual los convenientes agasajos y refrescos para cada ocasión de visita. Más detallado y preciso constan los que se han de dar cuando se celebra que habrá boda:

Para el gusto habrá ricas bebidas,

En cristalinos vasos dirigidas;

Ramilletes suaves con primores, Habrá de dulces secos, no de flores, agua clara y fría, que es de corte, aunque traiga cabambanos del Norte, chocolate en xicara de a vara, ... Y para concluir este agasajo habrá lo regular, que es el cascajo de bollos, de vizcochos de tostadas, $y$ otros melindres, con roscas regaladas ${ }^{63}$.

En las demás ocasiones se refieren semejantes productos pero en menor cantidad y con menos protocolo en el servicio.

La referencia a estos consumos es indicativa de la trascendencia que las mujeres y las «visitas de estrado» tenían en la demanda sobre los referidos productos. Por supuesto no era un consumo exclusivo pero la necesidad de responder a un protocolo establecido hacía que las mujeres de clase media y sobre todo alta, estimularan el mercado de estas delicias para el paladar.

Todas las posibilidades de relación que se habían ido introduciendo en los estrados para estímulo de la vida social de la mujer estuvieron en la base misma de su desaparición como espacio de recogimiento femenino y de acceso restringido a los varones. Los testimonios del siglo XVIII insisten en el abandono de la aguja, por más que tratara de ensalzarla la misma Josefa Amar y Borbón; por el contrario lo que proliferaba en los espacios domésticos de sociabilidad femenina eran las visitas, los refrescos y entretenimientos como la conversación, la música y la danza (convertidas cada vez más en prerrogativa de las mujeres). Esas mismas actividades favorecían la ruptura del aislamiento y el contacto no sólo entre las damas sino también con los varones, favoreciendo la pérdida de sentido que antes tuviera la separación de espacios domésticos, aunque la costumbre imponía todavía comportamientos tradicionales que estaban en vías de superación, a caballo entre el «estrado» y el «salón». Un autor del XVIII afirmaba que

Los refrescos... no contribuyen más que las tertulias a multiplicar las relaçiones entre los dos sexos... A medida que llegan los invitados, los hombres se separaran de las mujeres. Éstas van a sentarse en una habitación

${ }^{63}$ El ceremonial de estrados ..., p. 20. 
donde la etiqueta las hace estar juntas hasta que todo el mundo se ha reunido, o por lo menos los hombres están de pie sin acercárseles. La dueña de la casa les espera en un sofá en un lugar determinado de un salón, que, en las costumbres antiguas, aún subsistentes en parte, recibía el nombre de estrado y sobre el cual suele estar colgada una imagen de la Virgen. La aparición del refresco relaja los rostros y los corazones, la conversación se anima y los sexos se aproximan ${ }^{64}$.

El siglo XVIII presencia un proceso de subversión de valores y su influencia en gustos y comportamientos, como ha descrito con claridad Martín Gaite en la obra reiteradamente citada: se recibía más, a más gente y más frecuentemente; los bailes reunían a mujeres y hombres que estaban en contacto físico, y en los salones se encontraban también sin separación de sexos. Las mujeres salían con más frecuencia y su vista era motivo de lujo y ostentación. Naturalmente los cambios fueron progresivos, más sutiles en provincias que en la corte ${ }^{65}$, e imperceptibles en los ámbitos rurales. Pero allí donde se fueron generalizando trastocaron el sentido de los estrados femeninos domésticos.

${ }^{64}$ Jean François Bourgoing, Nouveau voyage en Espagne ou tableau de l'état actuel de cette monarquie, París, Regnault, 1788, t. II, p. 315.

${ }^{65}$ Jesusa Vega ha estudiado el caso de Madrid en el siglo XVIII y comenta cómo la progresiva desaparición del estrado hizo que muchos se pusieran completos a la venta, ofertándose mediante anuncio en el Diario de Madrid («Transformación del espacio doméstico en el Madrid del siglo XVIII: del oratorio y el estrado al salón», Revista de Dialectología y Tradiciones Populares, vol. LX, 2005, n. 2, pp. 191-226). 